\title{
Addressing Biases in Patient Care with The 5Rs of Cultural Humility, a Clinician Coaching Tool
}

\author{
Christie Masters, MD, MBA, MHA, BCC, SFHM ${ }^{7}$, Dea Robinson, MA, FACMPE ${ }^{2}$, \\ Sally Faulkner, RN, MSN, FHM ${ }^{3}$, Eltanya Patterson, MD ${ }^{4}$, Thomas Mcllraith, MD, SFHM, CLHM ${ }^{5}$, and \\ Aziz Ansari, DO, SFHM, FACP'
}

'UCLA Hospitalist Service, UCLA Medical Center, Los Angeles, CA, USA; ${ }^{2}$ Organizational Learning, Performance and Change, Colorado State University, Fort Collins, CO, USA; ${ }^{3}$ NorthShore University Health Systems, Evanston, IL, USA; ${ }^{4}$ Charleston Area Medical Center, Charleston, WV, USA; ${ }^{5}$ Mercy Medical Group, Sacramento, CA, USA; ${ }^{\circ}$ Division of Hospital Medicine, Loyola University Medical Center, Maywood, IL, USA.

Clinicians are called to care for patients with increasingly diverse backgrounds during vulnerable moments when gaining trust is imperative. Simultaneously, implicit or unconscious biases are omnipresent. Guidance for clinicians in addressing and curtailing implicit biases is a necessity to preserve provider resiliency while providing high-value, patient-centered care. However, tools to aid clinicians in this endeavor are unknown. The following article introduces The 5Rs of Cultural Humility (5Rs) as a coaching tool available to all clinicians, leaders, and administrators. It is a tool that brings awareness to the reality that everyone has implicit biases and provides a platform to address these biases through the use of cultural humility, mindfulness, and compassion. The tool encourages the clinician to become more aware of his or her decision-making and interactions with others. Each $\mathrm{R}$ includes an aim at reducing biases and a self-reflection question. The 5Rs are reflection, respect, regard, relevance, and resiliency. The framework of the 5Rs presents an approach for clinicians to explore more mindful interactions and enriching patient-provider interactions.

KEY WORDS: implicit biases; reflection; respect; regard; relevance; resiliency; cultural humility; society.

J Gen Intern Med 34(4):627-30

DOI: $10.1007 / \mathrm{s} 11606-018-4814-\mathrm{y}$

(c) Society of General Internal Medicine 2019

\section{INTRODUCTION}

Female, male. White, black. Citizen, immigrant. Cis, trans. Straight, gay. These are a few powerful terms used to identify and categorize people which knowingly and unknowingly influence human interactions. Implicit biases are attitudes that affect a person's understanding of others in an unconscious manner and lead to differential treatment of others. ${ }^{1,2}$ Clinicians are not immune to implicit biases. ${ }^{3-5}$ Manifestation of implicit biases affects the patient-provider relationship and can result in harm to patients and to providers alike. ${ }^{6}$ Routine

Received August 13, 2018

Revised November 20, 2018

Accepted December 14, 2018

Published online January 8, 2019 moments to pause, think, and reflect on care within this relationship have been called for in clinical practice. ${ }^{7}$

The 5Rs of Cultural Humility is a coaching tool created by a workgroup within the Society of Hospital Medicine's Practice Management Committee to provide clinicians with a concise framework to address implicit biases and choose a more mindful response. ${ }^{8}$ Though originally intended for hospitalists, it is a universal tool available for all to use. Focusing on cultural humility enables individuals to effectively approach cultural nuances and confront stereotypes.

The 5Rs include reflection, respect, regard, relevance, and resiliency. The tool incorporates skills identified at reducing implicit biases in health care, including perspective-taking, emotional regulation, and partnership-building. ${ }^{1,}{ }^{9}$ Each $\mathrm{R}$ includes a specific aim at reducing biases and provides the practitioner coaching via a self-reflection question. The following article briefly reviews implicit biases and cultural humility, describes application of this tool, and expounds on the tenets of the 5 Rs.

\section{IMPLICIT BIASES AND CULTURAL HUMILITY IN HEALTH CARE}

Acknowledging one's implicit biases and their influence is a complex phenomenon. ${ }^{4}$ Online assessments are available where individuals can uncover their biases. ${ }^{10}$ Clinicians' implicit biases may influence treatment decisions. ${ }^{4}$ Therefore, interventions are required to decrease any potential discrimination.

A recent Cochrane review analyzing cultural competency training and consequent patient-related outcomes revealed some positive results in decreasing biases. ${ }^{11}$ Despite the lack of negative studies in cultural competency training, though, the overall evidence remains insufficient to make definitive conclusions. $^{11}$

The practice of cultural humility, however, is the next step along the continuum of cultural knowledge. ${ }^{12}$ Unlike cultural competency, cultural humility does not require or assume expertise in any social group, institution, or belief system. Cultural humility is a life-long commitment to self- 
evaluation and self-critique in an effort to address power imbalances and to advocate for others. ${ }^{13}$ The practice of cultural humility helps mitigate implicit bias, promotes empathy, and aids the provider in acknowledging and respecting patients' individuality. ${ }^{13}$ The universality of cultural humility principles puts emphasis on the provider's need to connect instead of being an expert on the patient's race, culture, or ethnicity.

\section{APPLICATION OF THE 5RS}

The overall aim of The 5Rs of Cultural Humility is to bring more awareness into clinical encounters in an attempt to improve health care by decreasing disparities, improving the patient-clinician relationship, highlighting shared humanity, and building provider resilience. The tool has specific aims and asks that incorporate skills identified at reducing implicit biases in health care, such as perspective-taking, emotional regulation, and partnership-building. ${ }^{1,9}$

Asking the questions within the 5 Rs provides coaching. As such, the tool can be used in a variety of ways including selfcoaching, small group discussions, workshops, and peer-topeer coaching or counseling. The amount of time spent in reflection will vary with the setting in which the tool is used. A clinician may spend a few moments in self-reflection asking one or more of these questions during inpatient clinical rounds or between seeing patients in clinic. Whereas use of the tool to stimulate reflection, discussion, and further coaching can range from a few minutes to an hour or more in peer-to-peer counseling, group settings, or workshops.

\section{THE 5RS OF CULTURAL HUMILITY}

\section{Reflection}

Aim: Clinicians will approach every encounter with humility and understanding that there is always something to learn from everyone.

Ask: What did I learn from each person in that encounter?

Clinicians are experts within their field of practice. Approaching an encounter with humility embraces the understanding that there is more to learn in life outside of one's area of expertise. Reflection in practicing medicine requires the clinician to pause and consider what is available to learn from each situation and to connect meaning to those encounters. The associated question with this $\mathrm{R}$ coaches the clinician to identify what is available for him or her to learn beyond his or her current understanding of a situation.

Reflection is part of humility in practice. Humility can be conceptualized as doubt and self-deprecation. However, evidence supports that humility is perceived as a strength of character in exemplary clinical attendings. ${ }^{14}$ Reflection also provides a way for clinicians to make sense of difficult patient situations in relation to themselves. ${ }^{15}$ A reflective clinician has the ability to navigate personal emotional reactions to patient suffering and challenging patient care situations with an engaged concern and without losing a sense of self. ${ }^{15}$ Compassion is at the core of healing and highlights the shared humanity in all circumstances. The recognition of individuality within this interconnectedness allows practitioners of The 5Rs of Cultural Humility to learn from interactions with others. Intentional practice of self-reflection becomes a strength as it confronts clinician disengagement behaviors. ${ }^{16}$ Cultivating clinician reflection contributes to clinician well-being and perseverance in pursuing the passion to provide quality care.

\section{Respect}

Aim: Clinicians will treat every person with the utmost respect and strive to preserve dignity at all times.

Ask: Did I treat everyone involved in that encounter respectfully?

Respect is the process of honoring someone by exhibiting care, concern, or consideration for their needs or feelings. Respect extends to all individuals involved in a patient encounter, including other care providers, family members, and the individual clinician. ${ }^{17}$ The intention of this $\mathrm{R}$ is to aid the clinician during challenging circumstances. The associated question coaches the clinician to consider his or her actions and to determine if they align with the value of respect.

Individuals' knowledge about and decisions related to health care are personal, varied, and impacted by their environment, cultural beliefs, and socioeconomic status. ${ }^{18}$ Clinicians have a moral duty to treat patients with respect by incorporating patients' choices, preferences, and boundaries with evidence-based care. ${ }^{19}$ Respect allows patients to be active participants in decision-making regarding their care. It requires effort on the clinician's part to understand the patient's reasoning, to ask for clarity, and to offer guidance while understanding that patient expectations or decisions will not always align with the clinician's values or medical advice. Pausing to consider the $\mathrm{R}$ of respect supports a dignified environment and values each person as an individual human. ${ }^{19}$

\section{Regard}

Aim: Clinicians will hold every person in their highest regard, be aware of, and not allow unconscious biases to interfere in any interactions.

Ask: Did unconscious biases drive this interaction?

Clinicians are caring for patients with diverse backgrounds during vulnerable moments. Whether in a hospital or clinic, clinicians are increasingly strangers to patients and must build trust and rapport quickly. This 
connection can be achieved by holding a patient in the highest regard. The aim of regard is to value a patient for his or her individuality and belief system. The associated question with this $\mathrm{R}$ coaches the clinician to consider his or her own biases, implicit or known.

Having regard for patients requires an understanding that everyone has implicit biases, which affect an individual's understanding, actions, or decisions in an unconscious manner. ${ }^{2}$ Clinicians hold unconscious beliefs about various social and identity groups ${ }^{3-5}$ that places providers at risk for discrimination in making health care decisions. ${ }^{20}$ Additionally, biases from a clinician can potentially affect how a patient may perceive a clinician's verbal communication, degree of empathy, and non-verbal body language. ${ }^{21-23}$

Invoking regard for patients within the 5Rs framework raises awareness of potential biases and allows clinicians to recognize, neutralize, and modify thoughts before they manifest into behaviors. Patients who sense their individuality is held in high regard and feel understood are more likely to have trusting relationships with their clinicians. ${ }^{24}$ This trust leads to a more therapeutic patient-provider relationship.

\section{Relevance}

Aim: Clinicians will expect cultural humility to be relevant and apply this practice to every encounter.

Ask: How was cultural humility relevant in this encounter?

The relevancy of cultural humility is intertwined with the clinician's quest for quality and promotion of patient-centered care (PCC). The associated question with this R coaches one to consider the pertinence of cultural humility with other values in the health care system.

The Institute of Medicine advocates for the practice of timely and safe evidence-based medicine within a PCC model that chooses wisely and is impartial. ${ }^{25}$ Additionally, PCC is an expression of value-based purchasing, which is a Centers for Medicare and Medicaid incentive program that rewards hospitals based on quality of care rather than quantity; it incorporates quality measures, patient outcomes, and the patient experience. $^{26}$

The transformation necessary to improve health care and decrease disparities involves being more enlightened to the bio-psycho-social aspects of all patients. Relevance, in The 5Rs of Cultural Humility, coaches the clinician on how to advocate for his or her patients. The practice of cultural humility recognizes that patients have the ability to discuss, engage in, collaborate with, and choose their own plan of care. Embracing the relevance of cultural humility balances the power dynamic in this privileged relationship by acknowledging that the patient and the clinician are both valued in the partnership.

\section{Resiliency}

Aim: Clinicians will embody the practice of cultural humility to enhance personal resiliency and global compassion.

Ask: How was my personal resiliency affected by this interaction?

Cultural humility allows clinicians to recognize that they are experts in their respective fields and that patients are the experts in how they live their lives. The aim and question associated with resiliency bring awareness to the humanity of the clinician, patient, and all involved in the encounter. The associated question with this $\mathrm{R}$ coaches clinicians to consider self-care.

In an era where clinician burnout is reaching epidemic numbers, creating interventions and identifying tools to increase resiliency is an imperative. ${ }^{27}$ Of the three burnout components, physicians appear to be at most risk of experiencing depersonalization and emotional exhaustion during difficult encounters. ${ }^{28}$ During these encounters, the potential risk of burnout can be counteracted through the practice of cultural humility. This R highlights the importance of extending compassion to self, as well as others, during suffering. Pausing to examine one's personal state affects patient care by influencing subsequent communication and interactions. Encouraging and implementing practices that improve communication decreases the risk of burnout while increasing connection with patients. $^{29}$

\section{FURTHER RESEARCH}

The mutual value and benefit for clinicians and patients associated with implementation of The 5Rs of Cultural Humility remains at a conceptual level. However, real-time, anonymous polling during a formal presentation of this framework to attendees at the Society of Hospital Medicine's 2018 conference reveals a desire for more time, attention, and training regarding how to implement the 5 Rs into professional practice. Therefore, further empirical research is needed. ${ }^{30}$ Testing the 5Rs will contribute to knowledge about mitigating implicit bias in a field where there is no established methodology. ${ }^{30}$ Examples for further research include quantitative patient satisfaction scoring, as well as qualitative methods to assess the intended outcomes of improving patient care and clinician resiliency. These approaches will provide needed feedback for physicians who have adopted the 5Rs into their professional practice.

\section{CONCLUSION}

Clinicians are not immune to implicit biases, which can negatively affect the patient-provider relationship and can result in harm to patients and to providers alike. The practice of cultural humility helps mitigate implicit bias, promotes empathy, and 
aids the clinician in acknowledging and respecting patients' individuality. The 5 Rs of Cultural Humility is a coaching tool that provides clinicians with a concise framework to begin addressing implicit biases and choosing a more mindful and compassionate response.

Corresponding Author: Aziz Ansari, DO, SFHM, FACP; Division of Hospital Medicine Loyola University Medical Center, Maywood, IL, USA (e-mail: Aansar1@lumc.edu).

\section{Compliance with Ethical Standards:}

Conflict of Interest: The authors declare that they do not have a conflict of interest.

Publisher's Note: Springer Nature remains neutral with regard to jurisdictional claims in published maps and institutional affiliations.

\section{REFERENCES}

1. The Joint Commission, Quick Safety. Implicit bias in health care. Available at: https://www.jointcommission.org/assets/1/23/Quick Safety_Issue_23_Apr_2016.pdf. Accessed 28 Nov 2018.

2. Devine P. Stereotypes and Prejudice: their automatic and controlled components. J Pers Soc Psychol. 1989;56(1):5-18.

3. Chapman EN, Kaatz A, Carnes M. Physicians and implicit bias: how doctors may unwittingly perpetuate health care disparities. J Gen Intern Med. 2013;28(11):1504-10.

4. FitzGerald $\mathbf{C}$, Hurst $\mathbf{S}$. Implicit bias in healthcare professionals: a systematic review. BMC Med Ethics. 2017;18(1): 19.

5. Sabin J, Nosek BA, Greenwald A, Rivara FP. Physicians' implicit and explicit attitudes about race by MD race, ethnicity, and gender. J Health Care Poor Underserved. 2009;20(3):896-913.

6. Van Ryn M, Burgess DJ, Dovidio JF, Phelan SM, Saha S, Malat J, et al. The Impact of Racism on Clinician Cognition, Behavior, and Clinical Decision Making. Du Bois Rev. 2011;8(1):199-218.

7. Ship AN. "Thinking Time": Doctor Envies Curlers. J Gen Intern Med. 2018 33(8): 1212.

8. Society of Hospital Medicine. The 5Rs of Cultural Humility. Available at: https://www.hospitalmedicine.org/practice-management/the-5-rs-ofcultural-humility/. Accessed 28 Nov 2018.

9. Galinsky AD, Moskowitz GB. Perspective-taking: decreasing stereotype expression, stereotype accessibility, and in-group favoritism. J Pers Soc Psychol. 2000;78(4):708-24.

10. Project Implicit. Available at: https://implicit.harvard.edu/implicit/. Accessed 28 Nov 2018.

11. Horvat L, Horey D, Romios P, Kis-Rigo J. Cultural competence education for health professionals. Cochrane Database Syst Rev. 2014;(5):CD009405.

12. Dore A EA. Cultural learning in healthcare: recognizing \& navigating the difference. ISBN: 9780991607143. Atlanta: North American Business Press; 2015

13. Tervalon M, Murray-Garcia J. Cultural humility versus cultural competence: a critical distinction in defining physician training outcomes in multicultural education. J Health Care Poor Underserved. 1998;9(2):11725.

14. Houchens N, Harrod M, Moody S, Fowler K, Saint S. Techniques and Behaviors Associated with Exemplary Inpatient General Medicine Teaching: An Exploratory Qualitative Study. J Hosp Med. 2017;12(7):503-9.

15. Charon R. The patient-physician relationship. Narrative medicine: A model for empathy, reflection, profession, and trust. JAMA. 2001;286(15):1897-902.

16. Phillips SP, Dalgarno N. Professionalism, professionalization, expertise and compassion: a qualitative study of medical residents. BMC Med Educ. 2017;17(1):21.

17. Spagnoletti CL, Arnold RM. R-E-S-P-E-C-T: even more difficult to teach than to define. J Gen Intern Med. 2007;22(5):707-9.

18. Dickert NW, Kass NE. Understanding respect: learning from patients. J Med Ethics. 2009;35(7):419-23.

19. Beach MC, Duggan PS, Cassel CK, Geller G. What does 'respect' mean? Exploring the moral obligation of health professionals to respect patients. J Gen Intern Med. 2007;22(5):692-5.

20. Green AR, Carney DR, Pallin DJ, Ngo LH, Raymond KL, Iezzoni LI, et al. Implicit bias among physicians and its prediction of thrombolysis decisions for black and white patients. J Gen Intern Med. 2007;22(9): 1231-8.

21. Cooper LA, Roter DL, Carson KA, Beach MC, Sabin JA, Greenwald AG, et al. The associations of clinicians' implicit attitudes about race with medical visit communication and patient ratings of interpersonal care. Am J Public Health. 2012;102(5):979-87.

22. Elliott AM, Alexander SC, Mescher CA, Mohan D, Barnato AE Differences in Physicians' Verbal and Nonverbal Communication With Black and White Patients at the End of Life. J Pain Symptom Manag. 2016;51(1): 1-8.

23. Penner LA, Dovidio JF, West TV, Gaertner SL, Albrecht TL, Dailey RK, et al. Aversive Racism and Medical Interactions with Black Patients: A Field Study. J Exp Soc Psychol. 2010;46(2):436-40.

24. Keating NL, Gandhi TK, Orav EJ, Bates DW, Ayanian JZ. Patient characteristics and experiences associated with trust in specialist physicians. Arch Intern Med. 2004;164(9):1015-20.

25. Committee on Quality of Health Care in America. Institute of Medicine. Crossing the Quality Chasm: A New Health System for the 21st Century. Washington, DC: National Academy Press; 2001.

26. Centers for Medicare and Medicaid Services. The Hospital Value-Based Purchasing (VBP) Program. Available at: https://www.cms.gov/Medicare/Quality-Initiatives-Patient-Assessment-Instruments/Value-BasedPrograms/HVBP/Hospital-Value-Based-Purchasing.html. Accessed 28 Nov 2018.

27. Linzer M, Baier Manwell L, Mundt M, Williams E, Maguire A, McMurray J, et al. Organizational climate, stress, and error in primary care: The MEMO study. In: Henriksen K, Battles JB, Marks ES, Lewin DI, eds. Advances in Patient Safety: From Research to Implementation (Volume 1: Research Findings). Rockville (MD); 2005.

28. Sierra-Siegert M, David AS. Depersonalization and individualism: the effect of culture on symptom profiles in panic disorder. J Nerv Ment Dis. 2007; 195(12):989-95.

29. Boissy A, Windover AK, Bokar D, Karafa M, Neuendorf K, Frankel RM, et al. Communication Skills Training for Physicians Improves Patient Satisfaction. J Gen Intern Med. 2016;31(7):755-61.

30. Blair IV, Steiner JF, Havranek EP. Unconscious (implicit) bias and health disparities: where do we go from here? Perm J. 2011;15(2):71-8. 